\title{
Motives underlying food choice: dentists, porters and dietary health promotion
}

\author{
M.L. Crossley, ' and S.N. Khan, ${ }^{2}$
}

\begin{abstract}
Objective Differences in dental decay and disease amongst socioeconomic groups are thought to derive, in part, from variations in dietary practices and differences in education. The aim of this exploratory study was to examine whether differences in motivating factors affecting food choice could be found in a comparison of two groups at very different ends of the social spectrum: dentists and porters/cleaners.
\end{abstract}

Design A convenience sample of 100 people (51 porters/cleaners and 49 dentists) working in the dental school at a university in the North West of England were approached to interview face-to-face and complete the Food Choice Questionnaire (FCQ), a previously validated measure designed to assess nine main factors relevant to peoples' food choices. A sample size of 100 was chosen because it was adequate to test validity (using a two-group Chi-square test with a 0.050 two sided significance).

Results Findings were analysed using independent sample $t$-test and multiple linear regression. Results indicated significant differences between porters/cleaners and dentists in terms of their motives for food choice on six of the nine FCQ factors. These included convenience $(\mathrm{p}<0.001)$, natural content $(\mathrm{p}<0.05)$, price $(\mathrm{p}<0.005)$, familiarity $(\mathrm{p}<.0001)$, mood $(\mathrm{p}<0.03)$ and ethical concern $(\mathrm{p}<0.01)$. Porters/cleaners tended to rate the factors covenience, price, mood and familiarity more highly, whereas dentists did the same for natural content and ethical concern.

Conclusions Awareness of the differences in motivational factors affecting food choice between different social groups is important to dental practitioners who are being taught to play an increasing role in health promotion. If dental practitioners are to partake meaningfully in such a role, it is necessary for them to be aware not only of their own motives in food selection, but also of the way in which those motives may differ from those of their clients.

\begin{abstract}
long with other health professionals, dentists are being encourAaged to take a more active part in health promotion and education. The pursuit of a more 'holistic' dentistry and the increasing focus on promoting oral health as part of a 'Common Risk Factor Approach' incorporates a particular emphasis on diet and educating people to eat in more healthy ways. ${ }^{1}$ From a specifically dental point of view, this is especially important in the light of differing degrees of dental decay amongst different socioeconomic groups. ${ }^{2-4}$ Some studies have suggested that these differences may be attributable to variations in dietary practices. ${ }^{4-10}$
\end{abstract}

$1^{*}$ Lecturer in Behavioural Sciences, Turner Dental School, University of Manchester, Higher Cambridge Street, Manchester, M15 6FH; ${ }^{2}$ Vocational Trainee, 10 Dental, 10 Scarisbrick New Road, Southport, PR9 OHE

${ }^{*}$ Correspondence to: $M$. L. Crossley

REFEREED PAPER

Received 8.01.01; Accepted 02.04.01

(c) British Dental Journal 2001; 191: 198-202
As with many other areas of health, explanations for differences in diet and dietary related behaviours have revolved around whether the factors that account for these differences are individual (psychological) or collective (social and cultural). For instance, in terms of food choice and selection, some research has focussed on cultural forces such as food production, manufacture, marketing, delivery and sale. ${ }^{11}$ By contrast, more individually focused explanations tend to pay attention to psychological factors determining health related behaviours. In terms of food choice, various motivating factors such as taste, sensory appeal, habit, weight control, ethical concern and stress have been shown to influence food selection. ${ }^{12}$ Such explanations do not, however, suggest that such motivating factors are determined at the level of the individual. On the contrary, recent research has suggested that such motivating factors differ significantly amongst people with different levels of education and in different socioeconomic groupings. ${ }^{13}$

If dietary differences amongst socioeconomic groups can, in part, be attributed to individual motivating factors (which are influenced by wider social forces), then it seems only a small step to promote health education as the route to improved diet and (oral) health. However, recent developments in health psychology have indicated that a simplistic focus on information and education remains insufficient. ${ }^{14}$ This is partly because health is not the only factor that people take into account when making choices about food and other health related issues. An exclusive focus on health may, therefore, lead health professionals to emphasise a set of motives that are of limited significance for many people. ${ }^{12}$ Accordingly, it has been recognised that it is important to explore the role of other influences on health related behaviours. More effective implementation of health promotion strategies may depend on recognition of the status of health in comparison with other motives. It was in the light of these concerns that Steptoe et al. ${ }^{12}$ developed the Food Choice Questionnaire (FCQ), a measure capable of assessing the relative importance of various motivating factors on food choice.

This paper works from the premise that if dentists are to be involved in health promotion related to dietary practices, then it is necessary for them to be aware not only of their own motives in food selection, but also of the way in which those motives may differ from those of their clients. Accordingly, it reports the results of a smallscale pilot study whose aim was to determine whether people at two different ends of the socioeconomic spectrum made food choices in relation to different motivational factors. This was achieved by using occupation as an indicator for socioeconomic grouping. Accordingly, a convenience sample of dentists (higher socioeconomic grouping) and auxiliary staff (porters and cleaners - lower socioeconomic grouping) were asked to complete the FCQ. Differences between their responses were then analysed. In addition, differences between men and women were analysed, in order to ascertain if gender significantly affected motivation with regard to food choice. 


\section{Method}

Sample

A convenience sample of 100 people working in a university dental school in the North West of England were approached to interview face-to-face and complete the FCQ. The sample size of 100 was chosen because it was adequate to test validity. It was based on a calculation of the proportion of participants responding that it was 'moderately to very important' that the food they ate on a typical day 'keeps me healthy' (item 29 from the FCQ, see below). A twogroup chi-squared test with a 0.050 two-sided significance will have $86 \%$ power to detect the difference between a Group 1 proportion $\pi_{1}$ of 0.700 (porters/cleaners) and a Group 2 proportion $\pi_{2}$ 0.400 (dentists) when the sample size of each group is 50 .

\section{Procedure}

This involved approaching as many dentists and porters/cleaners as possible until the appropriate quota had been reached. Of the 100 participants who took part in the study, 49 were dentists and 51 porters or cleaners. The sample included 53 men and 47 women. In the porter/cleaner group, there were 29 women and $22 \mathrm{men}$. In the group of dentists, there were 35 men and 14 women. Respondents ranged in age from 28-63 (mean 49.2, SD 9.3).

\section{The Food Choice Questionnaire}

The Food Choice Questionnaire (FCQ) was administered to participants. It was designed to assess a wide range of considerations relevant to people's food choices. Participants were asked to endorse the statement: 'It is important to me that the food I eat on a typical day...' for 36 separate items by choosing between four responses scored 1-4: not at all important, a little important, moderately important, and very important (Table 1).

In the original development of the FCQ (Steptoe et al. ${ }^{12}$ ), Factor Analysis with Varimax Rotation was used to reduce the 36 items to nine general factors which accounted for $65.2 \%$ of the variance. The internal consistency of the FCQ was reasonably high, with Cronbach $\alpha$ scores being above 0.70 on all factors. Development of the scale resulted in a test-retest reliability $>0.70$, suggesting that the reliability of the scales was acceptable. Scores on each factor were computed by adding up the individual items relating to each factor and then dividing by the number of items relating to each factor. This gave a score on each factor ranging from a minimum of 1 to a maximum of 4 . The resulting distribution of the factor scores revealed a bell-shaped normal distribution.

\section{Analysis}

Results were analysed using independent sample $t$-test in order to ascertain differences between the two occupational groups and genders with regard to factors motivating food choice. As certain of the factors differed significantly in relation to both occupational group and gender, multiple linear regression models were fitted in order to ascertain the relative importance of these two factors to the variance in scores.

\section{Results}

Table 2 illustrates the comparison between porters/cleaners and dentists in terms of their motives for food choice. These differences achieved statistical significance on six of the nine FCQ factors. These included: convenience $(\mathrm{p}<0.001)$, natural content $(\mathrm{p}<0.05)$, price $(\mathrm{p}<0.005)$, familiarity $(\mathrm{p}<.0001)$, mood $(\mathrm{p}<0.03)$ and ethical concern $(\mathrm{p}<0.01)$. Porters/cleaners tended to rate the factors covenience, price, mood and familiarity more highly, whereas dentists did the same for natural content and ethical concern.

Table 3 illustrates differences related to gender. Comparisons between men and women yielded significant differences in three of the nine FCQ factors. These included convenience $(\mathrm{p}<0.0005)$,
Table I Items on the FCQ (Food Choice Questionnaire)
Factor I Health
22. Contains a lot of minerals and vitamins
29. Keeps me healthy
10. Is nutritious
27. Is high in protein
30. Is good for my skin/teeth/hair/nails
9. Is high in fibre and roughage

\section{Factor 2 Mood}
16. Helps me cope with stress
34. Helps me cope with life
26. Helps me relax
24. Keeps me awake/alert
13. Cheers me up
31. Makes me feel good

Factor 3 Convenience

I. Is easy to prepare

15. Can be cooked very simply

28. Takes no time to prepare

35. Can be bought close to where I live or work

II. Is easily available in shops or supermarkets

\section{Factor 4 Sensory appeal

\author{
14. Smells nice \\ 25. Looks nice \\ 18. Has a pleasant texture \\ 4. Tastes good
}

\section{Factor 5 Natural content}

2. Contains no additives

5. Contains natural ingredients

23. Contains no artificial ingredients

Factor 6 Price
6. Is not expensive
36. Is cheap
12. Is good value for money

Factor 7 Weight control

3. Is low in calories

17. Helps me control my weight

7. Is low in fat

Factor 8 Familiarity

33. Is what I usually eat

8. Is familiar

2I. Is like the food I ate when I was a child

\section{Factor 9 Ethical concern}

20. Comes from countries I approve of politically

32. Has the country of origin clearly marked

19. Is packaged in an environmentally friendly way

price $(\mathrm{p}<0.006)$ and familiarity $(\mathrm{p}<0.01)$, with women being more likely to be motivated by these factors than men.

The factors convenience, price and familiarity differed significantly in relation to both occupational grouping and gender. Accordingly, multiple regression models were fitted for each of the following factors.

\section{Convenience}

A multiple linear regression model was fitted to the dependent variable convenience, with gender and occupation as independent variables. The model was significant $(F(2,97)=10.834, \mathrm{p}<0.0005)$, with gender contributing to an $R^{2}=0.12$, increasing to 0.18 with the addition of occupation. Accordingly, gender accounts for about 
Table 2 Mean scores on food choice factors in relation to occupational group (Figures in bold show overall priority of factor for each group in determining food choice)

\begin{tabular}{llllllll}
\hline Scale & \multicolumn{3}{l}{ Porters/cleaners } & \multicolumn{2}{l}{ Dentists } & P-value \\
\hline & Mean & s.d & \multicolumn{2}{l}{ Mean } & s.d & \\
\hline Health & 2.7 & $\mathbf{4}$ & 0.7 & 2.7 & $\mathbf{2}$ & 0.67 & 0.68 \\
Mood & 2.2 & $\mathbf{7}$ & 0.71 & 1.9 & $\mathbf{8}$ & 0.66 & 0.03 \\
Convenience & 3.0 & $\mathbf{3}$ & 0.76 & 2.6 & $\mathbf{3}$ & 0.67 & 0.00 \\
Sensory appeal & 3.3 & $\mathbf{I}$ & 0.5 & 3.1 & $\mathbf{I}$ & 0.57 & 0.16 \\
Natural content & 2.1 & $\mathbf{8}$ & 0.8 & 2.4 & $\mathbf{5}$ & 0.8 & 0.05 \\
Price & 3.1 & $\mathbf{2}$ & 0.7 & 2.2 & $\mathbf{6}$ & 0.57 & 0.00 \\
Weight control & 2.3 & $\mathbf{5 / 6}$ & 0.9 & 2.5 & $\mathbf{4}$ & 0.8 & 0.15 \\
Familiarity & 2.3 & $\mathbf{5 / 6}$ & 0.7 & 1.8 & $\mathbf{9}$ & 0.7 & 0.00 \\
Ethical concern & 1.6 & $\mathbf{9}$ & 0.6 & 2.0 & $\mathbf{7}$ & 0.9 & 0.01 \\
\hline
\end{tabular}

$12 \%$ of the variance in convenience ratings whereas occupation accounts for an additional $6 \%$.

\section{Price}

A multiple linear regression model was fitted to the dependent variable price, with gender and occupation as independent variables. The model was significant $(F(2,97)=27.343, \mathrm{p}<0.0005)$, with gender contributing to an $R^{2}=0.07$, this increasing to 0.4 with the addition of occupation. This indicates that gender accounts for about $7 \%$ of the variance in price ratings, whereas occupational grouping accounts for an additional $28 \%$.

\section{Familiarity}

A multiple linear regression model was fitted to the dependent variable familiarity, with gender and occupation as independent variables. The model was significant $(F(2,97)=7.791, \mathrm{p}<0.001)$, with occupational group contributing to an $R^{2}=0.11$, increasing to 0.14 with the addition of gender. Accordingly, occupational grouping accounts for approximately $11 \%$ of the variance in familiarity ratings, whereas gender accounts for only about $2 \%$.

\section{Discussion}

One explanation put forward for differences in motives for food choice has been that of 'resources and risks.' ${ }^{12}$ This basically means that those in society with more resources, in terms of money and spare time, tend to be able to take more 'risks' with food selection in terms of cost, experimentation and taking account of concerns other than the basic functional and utilitarian concerns of eating. This explanation has been used to account for differences in food choice motivation factors between different socioeconomic groups and between men and women. For instance, in terms of this argument, compared with people in higher socioeconomic groups, those in lower socioeconomic groups choose familiar, low cost and convenience foods because their time and money resources are relatively low. Likewise, women will tend to do the same because in the UK they typically have primary responsibility for food shopping and child-care and are therefore less 'time rich' than men. To what extent are the findings in this study consistent with this explanation?

In this investigation as in previous studies ${ }^{12}$, price was an obvious influence on food choice. The cost of food was a significantly more important element in selection amongst porters/cleaners compared with dentists (Table 1). The difference was characterised by a number of comments made by participants during the course of being interviewed. Whereas most participants made comments to the effect that 'the food I buy has to be good value for money', one male dentist reported that his financial position was such that he had all his food cooked in restaurants and another that if I wanted to I could eat out every night'. Price was also rated as significantly more important amongst women than men. This again confirms previous studies ${ }^{12}$ which have suggested that women's primary responsibility for food shopping makes them more aware of budgetary
Table 3 Mean scores on food choice factors in men and women

\begin{tabular}{|c|c|c|c|c|c|c|c|}
\hline \multirow{3}{*}{$\begin{array}{l}\text { Scale } \\
\text { Health }\end{array}$} & \multicolumn{3}{|c|}{ Men } & \multirow{2}{*}{\multicolumn{3}{|c|}{$\begin{array}{l}\text { Women } \\
\text { Mean }\end{array}$}} & \multirow{3}{*}{$\begin{array}{l}p \text {-value } \\
\text { s.d } \\
0.33\end{array}$} \\
\hline & \multicolumn{2}{|c|}{ Mean } & \multirow{2}{*}{$\begin{array}{l}\text { s.d } \\
0.6\end{array}$} & & & & \\
\hline & 2.7 & 2 & & 2.8 & 4 & 0.76 & \\
\hline Mood & 2.0 & 7 & 0.67 & 2.2 & $7 / 8$ & 0.72 & 0.11 \\
\hline Convenience & 2.6 & 3 & 0.76 & 3.1 & 2 & 0.63 & 0.00 \\
\hline Sensory appeal & 3.1 & I & 0.55 & 3.3 & I & 0.69 & 0.11 \\
\hline Natural content & 2.3 & $5 / 6$ & 0.81 & 2.2 & $7 / 8$ & 0.86 & 0.45 \\
\hline Price & 2.5 & 4 & $0.7 \mathrm{I}$ & 2.9 & 3 & 0.79 & 0.00 \\
\hline Weight control & 2.3 & $5 / 6$ & 0.77 & 2.5 & 5 & 0.71 & 0.30 \\
\hline Familiarity & 1.9 & 8 & 0.6 & 2.3 & 6 & 0.76 & 0.01 \\
\hline Ethical concern & 1.8 & 9 & 0.74 & 1.8 & 9 & 0.84 & 0.71 \\
\hline
\end{tabular}

limitations than men who show a more spontaneous pattern of food purchases.

On the familiarity factor, mean scores were significantly different amongst men and women, with women tending to score more highly. Previous studies ${ }^{13}$ have also found significant differences amongst income groups with regard to familiarity ratings. This study is again consistent with these findings. Porters/cleaners were significantly more likely to choose food in accordance with familiarity considerations in comparison with dentists.

In terms of the convenience factor, Rappoport et al. ${ }^{15}$ found that health motives were negatively correlated with convenience. Steptoe et al. ${ }^{12}$ were unable to confirm this, finding no such association. In the present study, Rappoport's earlier negative correlation between health and convenience was confirmed, although not reaching statistical significance (Table 4). The convenience factor was significantly related to both occupational grouping and gender, with porters/cleaners and women rating this factor as more important than dentists and men, respectively.

Multiple linear regression analysis related to the above factors revealed further that the salience of price and familiarity was most important for porters/cleaners, whereas variance in the convenience factor was accounted for mainly by gender. One explanation for this finding is that women, regardless of occupational status, tend to do most of the shopping thus rating convenience more highly than men.

The natural content scale reflects concern with the use of additives and the selection of natural ingredients and the ethical concern factor contains items relating to environmental and political issues. Both scales therefore reflect concerns beyond the basic functional and utilitarian concerns of food intake. Responses to both of these scales could be interpreted as supportive of the 'resources and risks' hypothesis. The correlation between the health and natural contents factor was high ( $r=0.59$ in the original study, $r=0.53$ in this study, see Table 4), suggesting a strong association between the two. Dentists had higher scores in relation to the natural content factor. As in previous studies, ${ }^{13}$ ratings of ethical concern differed significantly amongst socioeconomic groups (Table 2). Consistent with the 'risks and resources' hypothesis, dentists demonstrated higher levels of ethical concern. Many of the dentists were boycotting food from France, in contrast to the comment of one porter who, when asked, said he had, 'never even thought about it'.

Taken together, the findings in relation to these five factors price, familiarity, convenience, natural content and ethical concern - tend to lend support to the 'resources and risks' hypothesis. By contrast, results from the other four factors - sensory appeal, mood, weight control and health - are somewhat more spurious.

For instance, in relation to sensory appeal, the study by Steptoe et al. ${ }^{12}$ found that lower income groups tend to rate sensory appeal as less important than do the better off participants. This was explained in terms of the 'resources and risks' theory - people with less disposable income are unable to take taste into consideration 
and have to set other priorities in their selection of food. However, the findings of this study call this explanation into question because the sensory appeal factor was rated by all groups as the most important factor affecting food choice (Table 2) and ratings did not differ significantly amongst the two occupational groupings. Moreover, in contrast to previous studies which did not find any association between health and sensory appeal, or only a small positive association $^{12}$, this study found a strong, significant, positive association between health and sensory appeal (Table 4).

This leads to a consideration of the results from factor 1 , the health scale. It was somewhat surprising to find no significant differences between the two occupational groups in relation to health as a priority in food choice, especially in light of the established link between health and socioeconomic status. However, it is important to remember that the sample for this study was taken from a university setting and this may account for people in the lower socioeconomic group (porters/cleaners) being more aware of the health dimensions relating to food choice. It may be that it is not so much income 'resources' which determine healthy eating choices but 'resources' related to education and awareness ${ }^{13}$. As one female cleaner commented 'you don't have to be rich to be healthy, and raw vegetables and fruit are actually very cheap'. However, even if it is the case that the porters/cleaners in this study were more aware, the findings are still surprising given that dentists are health professionals who one might expect to yield higher than average ratings on the health-related dimensions of food choice.

Another interesting finding in relation to the health factor is that this study failed to support results from previous studies which have demonstrated that women tend to pay more attention to health factors in their choice of food. ${ }^{12,16}$ This is not to suggest that the women in this study did not consider health factors important. Although the women's mean rating for health (2.8) was lower than in the study by Steptoe et al. ${ }^{12}$ (3.01), the women in this investigation still rated most of the health considerations important in their choice of food. And although failing to reach statistical significance, women's scores on the health factor were, on average, higher than the men's.

Finally, the mood factor contains items relating to general alertness and mood, relaxation and stress control. Previous research has suggested that mood and stress may play a role in determining not only the quantity of food consumed, but also the selection of foodstuffs. This is thought to be the case especially amongst women and people with low levels of education who may, because of their lack of alternative resources, use eating as a way of regulating emotions and maintaining emotional well-being. ${ }^{17,13}$ However, again, although women did on average have higher scores than men on the mood factor, this did not reach statistical significance. On the other hand, dentists did have significantly lower average scores on the mood factor than porters/cleaners.

Taken as a whole, therefore, it seems the results from the five factors convenience, familiarity, price, natural content and ethical concern support the 'risks and resources' hypothesis. In line with other studies, this investigation highlights the need to take account of the way in which food selection is differentially determined within different sectors of the population. Table 2 shows that porters/cleaners and dentists have different average priorities in terms of food choice. Whereas both sensory appeal and convenience are of priority importance to both groups, perhaps not surprisingly, price is a more important consideration to porters/cleaners, with health usurping the role of price amongst the dentists. This suggests that appropriate strategies for health promotion should be designed to take account of the priorities and needs expressed amongst different sectors of the population. ${ }^{12}$

As dental practitioners are encouraged to become more actively involved in health promotion, especially with regard to dietary practices, it is essential that they have an understanding of the personal and social factors motivating people to behave in various ways, and appreciate that people's choice of food may be determined by considerations different to their own. For instance, when dentists are discussing food choices and healthy alternatives with clients they should be mindful of the fact that the cost of food is, for many, an important consideration. Accordingly, it is necessary to provide clients with information not only about food that is good for their oral and general health, but also practical tips about how to buy such food cheaply. For instance, when purchasing fresh orange juice, many people think that the more well-known branded products are the more healthy alternative, simply because they are the most expensive. It appears that there is a widespread cultural conception that 'healthy' food costs more. However, in fact, the 'Basic' or 'Bettabuy' brands produced by many supermarket chains,

Table 4 Intercorrelations (x 100) between FCQ factors

\begin{tabular}{|c|c|c|c|c|c|c|c|c|}
\hline & Health & Mood & Convenience & Sensory appeal & Natural content & Price & Weight & Familiarity \\
\hline Mood & $\begin{array}{l}34^{*} \\
4 I^{* *}\end{array}$ & & & & & & & \\
\hline Convenience & $\begin{array}{l}14 \\
-3\end{array}$ & $\begin{array}{l}27 * \\
12\end{array}$ & & & & & & \\
\hline Sensory appeal & $\begin{array}{l}19 * \\
40 * *\end{array}$ & $\begin{array}{l}32 * \\
50 * *\end{array}$ & $\begin{array}{l}5 \\
7\end{array}$ & & & & & \\
\hline Natural content & $\begin{array}{l}59^{*} \\
53^{* *}\end{array}$ & $\begin{array}{l}28 * \\
16\end{array}$ & $\begin{array}{l}-5 \\
-16\end{array}$ & $\begin{array}{l}22^{*} \\
32 * *\end{array}$ & & & & \\
\hline Price & $\begin{array}{l}20 * \\
-5\end{array}$ & $\begin{array}{l}22 * \\
20 *\end{array}$ & $\begin{array}{l}32^{*} \\
\mathbf{5 2}^{*} *\end{array}$ & $\begin{array}{l}4 \\
9\end{array}$ & $\begin{array}{l}9 \\
-22 *\end{array}$ & & & \\
\hline Weight control & $\begin{array}{l}38^{*} \\
34^{* *}\end{array}$ & $\begin{array}{l}21 * \\
16\end{array}$ & $\begin{array}{l}7 \\
13\end{array}$ & $\begin{array}{l}2 \\
8\end{array}$ & $\begin{array}{l}31 * \\
19\end{array}$ & $\begin{array}{l}14 \\
3\end{array}$ & & \\
\hline Familiarity & $\begin{array}{l}9 \\
9\end{array}$ & $\begin{array}{l}34 * \\
39 * *\end{array}$ & $\begin{array}{l}29 * \\
35 * *\end{array}$ & $\begin{array}{l}13 \\
21 *\end{array}$ & $\begin{array}{l}8 \\
-14\end{array}$ & $\begin{array}{l}13 \\
37^{* *}\end{array}$ & $\begin{array}{l}-5 \\
\text { I }\end{array}$ & \\
\hline Ethical concern & $\begin{array}{l}37^{*} \\
23 *\end{array}$ & $\begin{array}{l}25 * \\
7\end{array}$ & $\begin{array}{l}12 \\
-9\end{array}$ & $\begin{array}{l}13 \\
-7\end{array}$ & $\begin{array}{l}39 * \\
38^{*} *\end{array}$ & $\begin{array}{l}22 * \\
-18\end{array}$ & $\begin{array}{l}9 \\
16\end{array}$ & $\begin{array}{l}10 \\
-13\end{array}$ \\
\hline
\end{tabular}

$* \mathrm{p}<0.01$

*** $\mathrm{p}<0.05$

(NB: Figures in bold relate to correlations found in this study, figures in normal type refer to correlations of original study ${ }^{12}$ ). 
although very cheap, generally contain less additives and added sugar than the more expensive branded products. The same is true of many other 'basic' line products such as tinned tomatoes, baked beans and dried pasta. Dentists could play a useful role in educating their clients about such food products.

However, the limitations of this study must be recognised. This was not a representative sample of either occupational group, but based on a small-scale pilot study in which as many people responded to the questionnaire as possible in a limited period of time. The occupational groups porters/cleaners and dentists were used as a marker of differences in income and socioeconomic grouping. However, it is important to recognise that differences reported between these groups could be due not just to differences in income and education, but also due to the specifically health oriented nature of the dental profession. In terms of a larger study, a random sample of different socioeconomic groups within both health related and non-health related occupations would be required. In addition, more information regarding other factors which may affect food choice, such as family composition (eg households with children, or whether people live with a partner) would be useful. Despite these qualifying remarks, however, the findings of this study are broadly in congruence with previous studies with regard to differences in priorities between people in different socioeconomic groupings and with differing degrees of education. ${ }^{13}$

Another problem is that the FCQ is concerned with the factors perceived as relevant to food choice and these factors do not necessarily reflect actual dietary behaviour. However, there is some research to suggest that attitudes and perceptions related to food choice are actually significant predictors of eating behaviour in both men and women. ${ }^{18-19}$

Finally, recent research has begun to question the dominant quantitative and survey methodologies that most research into food choice relies upon. Many other factors relevant to food choice remain inadequately covered in the FCQ. These include religious considerations, managing interpersonal relationships and the more general social and familial context in which food and eating take place. ${ }^{20}$ Some would argue that these more complex considerations and choices can only be properly investigated with more sensitive qualitative style approaches, others would argue that more traditional approaches need further refinement. Whatever, it is certainly clear that more detailed research into the complex factors determining food choice is required.
1 An Oral Health Strategy for England. Department of Health, 1994 London.

2 Hunter, B. Risk factors and dental caries. Int Dent J 1980; 38: 211-7.

3 Moynihan P, Holt D. The National Diet and Nutrition survey of 1.5 to 4.5 year old children: summary of the findings of the dental survey. Br Dent $\mathrm{J}$ 1996; 181: 328-32.

4 Sakki T, Knuttilia M, Antrila S. Lifestyle, gender and occupational status as determinants of dental health behaviour. J Clin Periodontol 1998; 25: 566-70.

5 Petridou E, Athanassouli T, Panagopoulos H, Revinthi K. Sociodemographic and dietary factors in relation to dental health amongst Greek adolescents. Community Dent Oral Epidemiol 1996; 24: 307-11.

6 Silver D. A longitudinal study of infant feeding practices, diet and caries related to social class in children aged 3 and $8-10$ years. Br Dent $J 1988$ : $164: 21$.

7 Hilund U. (1987). Relationship between diet related behaviour and caries in a group of 14-year-old Danish children. Community Dent Oral Epidemiol 1987: 15: 184-7.

8 Johansson L, Thelle D, Solvoll K, Bjorneboe G, Drevon C. Healthy dietary habits in relation to social determinants and lifestyle factors. Br J Nutrition 1999: 81: 211-20.

9 Laitinen S, Rasanen L, Vikari J, Akerblom H. Diet of Finnish children in relation to the family's socio-economic status. Scand J Soc Med 1995; 23: 88-94.

10 Braddon F, Wadsworth M, Davies J, Cipps H. Social and regional differences in food and alcohol consumption and their measurement in a national birth cohort. J Epidemiol Community Health 1988: 42: 341-49.

11 Fine B, Leopold E. The World of Consumption. London: Routledge, 1993.

12 Steptoe A, Pollard T, Wardle J. Development of a measure of the motives underlying the selection of food: The Food Choice Questionnaire. Appetite 1995; $25: 267-84$.

13 Steptoe A, Wardle J. Motivational factors as mediators of socioeconomic variation in dietary intake patterns. Psychology and Health 1999; 14: 391-403.

14 Crossley M. Rethinking Health Psychology. London: Open University Press, 2000 (in press).

15 Rappoport L, Peters G, Huff-Corzine L, Downey R. Reasons for eating: an exploratory cognitive analysis. Ecol Food and Nutrition 1992; 28: 171-79.

16 Van den Bree M. Food choice and quantity of food consumption in relation to relevant variables: Genetic analyses in older age sample. Dissertation Abstracts International: Section B: Sci and Eng 1995, 56(3-B): 1225.

17 Wardle J. Compulsive eating and dietary restraint. Br J Clin Psychol 1987, 26: 47-55.

18 Doyle E, Feldman R, Keller J. Nutrition, education and gender differences. Working with Brazilian adolescents. Health Values: J Health Behaviour, Education and Promotion 1995; 19: 10-17.

19 Conner, M. Accounting for gender, age and socioeconomic differences in food choice. Appetite 1994; 23: 195.

20 Stratton P, Bromley K. Families' accounts of the causal processes in food choice. Appetite 1999; 33:89-108. 